\title{
Primary Care Providers' Needs and Preferences for Information about Colorectal Cancer Survivorship Care
}

\author{
Talya Salz, PhD, Kevin C. Oeffinger, MD, Peter R. Lewis, MD, Robert L. Williams, MD, \\ Robert L. Rhyne, MD, and Mark W. Yeazel, MD
}

Background: The Institute of Medicine (IOM) proposed that cancer survivors and their primary care providers (PCPs) should receive survivorship care plans to inform ongoing care. We aimed to determine PCPs' preferences for the content of survivorship care plans for colorectal cancer (CRC) survivors.

Methods: PCPs in 3 practice-based research networks completed a survey regarding 45 topics of CRC information based on the IOM's survivorship care plan framework.

Results: One hundred fifty-six PCPs completed the survey. For 35 topics (78\%), at least half of respondents felt the topic was very important. Most PCPs reported receiving too little information about problems with chemotherapy $(68 \%)$ or radiation $(60 \%)$ and whether the oncologist intended to monitor for other cancers (71\%). PCPs widely agreed that they do not have enough information about increased risk of second CRCs, other cancers, and other diseases (78\%); long-term effects of chemotherapy (73\%) and radiation (67\%); and genetic counseling (83\%).

Conclusions: PCPs endorse the IOM's survivorship care plan framework as relevant and often report needing more information. Survivorship care plans may provide important information to PCPs by communicating patients' cancer histories and making recommendations regarding which aspects of care should be provided by the oncologist or the PCP. (J Am Board Fam Med 2012;25:635-651.)

Keywords: Cancer, Colorectal Cancer, Practice-based Research, Practice-based Research Networks, Primary Health Care, Survivors

Primary care providers (PCPs) are critical to cancer survivors' health, delivering general and preventive care and managing multiple conditions that may be unrelated to the cancer. However, PCPs may not

This article was externally peer reviewed.

Submitted 13 March 2012; revised 13 June 2012; accepted 18 June 2012.

From the Memorial Sloan-Kettering Cancer Center (TS, KCO); Penn State College of Medicine, State College, PA (PRL); University of New Mexico School of Medicine (RLW, RLR); and University of Minnesota (MWY).

Funding: This work was supported by a research grant from the National Cancer Institute (R03-CA-144682-01).

Prior presentation: Parts of this work were previously presented at the Minnesota Academy of Family Practice 2011 Annual Meeting; the American Society of Clinical Oncology 2011 Annual Meeting; the Agency for Healthcare Research and Quality's Practice-Based Research Network 2011 Annual Meeting; and the North American Primary Care Research Group 2011 Annual Meeting.

Conflict of interest: none declared.

Corresponding author: Talya Salz, MSKCC, Epidemiology and Biostatistics, 307 E 63rd St, 2nd Floor, New York, NY 10065 (E-mail: salzt@mskcc.org). feel confident in their ability to care for cancer survivors. They may lack relevant information about their patients' cancer treatment, the intended coordination of care with the oncologist, or general survivorship issues. Survivorship care plans are an intervention that can inform PCPs about the recommended care of cancer survivors. Proposed by the Institute of Medicine (IOM) in their report about cancer survivorship, From Cancer Patient to Cancer Survivor: Lost in Transition, survivorship care plans are documents that summarize a survivor's treatment history and recommended ongoing care. ${ }^{1}$ The authors of the IOM report recommend that oncologists give patients a survivorship care plan that they can then share with their PCPs. The use of survivorship care plans may benefit PCPs by promoting personalized and coordinated cancer survivorship care.

The IOM report enumerates detailed information to include in a survivorship care plan. The 
information generally falls into the following categories: a summary of the survivor's diagnosis and treatment, recommendations for ongoing care, and a listing of practical survivorship-related resources (such as support groups). As recipients of survivorship care plans, PCPs may or may not value all of this information. Also, PCPs may wish to receive additional information that is not suggested for inclusion in survivorship care plans. To maximize the usefulness of survivorship care plans for cancer survivors, we must better understand the perspectives of PCPs and refine the IOM framework for a survivorship care plan accordingly.

Survivorship care plans must ultimately be tailored to a specific cancer because not all categories of information in the IOM framework (such as descriptions of hormone receptor status, gene therapy, and familial risk) apply to all cancers. Furthermore, PCPs' needs and preferences for information may vary by disease site. Therefore, we focused our study on a single cancer: colorectal cancer (CRC). The involvement of PCPs is particularly important for CRC survivors, who comprise a large group with documented primary care needs. More than a million people are alive in the United States with a diagnosis of CRC, and with improved early detection and treatment, most live beyond the period of active cancer treatment. ${ }^{2,3}$ Although CRC survivors typically do not experience severe consequences of their cancer and therapy after the completion of treatment (distinguishing them from survivors of many other cancers), they do face ongoing medical and psychological challenges that may be addressed by a PCP. ${ }^{4-7}$ CRC survivors also receive poorer quality noncancer care, including less frequent receipt of general preventive health care, compared with individuals who do not have cancer. ${ }^{8}$ CRC survivors who visit a PCP receive more preventive care compared with survivors who do not visit a PCP. ${ }^{9,10}$ Preventive care is especially important in this population because the lifestyle risk factors for CRC (such as obesity) may also contribute to cardiovascular disease and other serious health problems unrelated to the cancer. To inform the refinement of the IOM framework for CRC, we conducted a survey of PCPs who have cared for CRC survivors to identify their informational needs and preferences for the content and delivery of CRC survivorship care plans.

\section{Methods \\ Design and Sample}

We implemented a cross-sectional survey of PCPs (physicians, physician assistants, and nurse practitioners) from a sample of 3 practice-based research networks (PBRNs) chosen to provide geographic and practice-setting diversity: one each in Minnesota, Pennsylvania, and New Mexico. PBRNs are networks of clinical practices that involve academic and community clinicians engaged in research on primary care. The Minnesota Academy of Family Physicians Research Network includes providers in all counties of Minnesota among 110 practices, $12 \%$ of which are academic practices. The Penn State Ambulatory Research Network encompasses 20 practices in both community and academic settings (86\% academic) in Central Pennsylvania. None are private practice. Research Involving Outpatient Settings Network includes providers in community health centers, Indian Health Services, and academic settings in 70 practices throughout New Mexico. Approximately one third are academic practices.

All nonpediatrician PCPs at each network were invited to participate in an anonymous online survey. Invitations to participate were sent via E-mail between July 2010 and April 2011. The invitations explained the study topic, that participation and responses were anonymous, and that the survey was deemed exempt from institutional review board review at their affiliated institution. Additional E-mailed invitations were sent to all participants between 3 and 6 times over a period of 2 to 6 months. We attempted to balance the proportion of respondents at each site and therefore extended the enrollment time and increased the number of invitations for sites that recruited more slowly. Interested PCPs could take the survey using log-in codes included in the E-mailed invitation. The survey began with questions screening for eligibility; PCPs who reported that they provided primary care and cared for at least one CRC survivor in their practice during the past year were deemed eligible to participate and automatically continued on to the survey itself.

\section{Instrument}

We designed a self-administered, Internet-based questionnaire assessing PCPs' opinions and informational needs for survivorship care plans (see the 
Appendix for the questionnaire). Using the IOM's framework for a survivorship care plan, we created 45 topics that were potentially relevant to CRC survivors. These topics fall into the categories of (1) patient-specific information about diagnosis, treatment, coordination of care, and medical reports, and (2) general CRC survivorship information. The questionnaire asked providers to consider the care of patients who completed active curative treatment for CRC and had no evidence of disease. The questionnaire elicited providers' opinions about (1) the importance of each topic, (2) whether the provider typically had enough information about this topic, and (3) preferences for the format and delivery of this information. For the items assessing importance, response options were "not important," "somewhat important," "very important," and "undecided." For the items regarding having enough information, the response options were "not enough," "just the right amount," "too much," and "it varies too much to say." The questionnaire assessed past receipt of categories of information in the IOM framework (summary of diagnosis, summary of treatment, recommendations of ongoing care from the PCP, and information about what aspects of care the PCP and oncology provider are responsible for). For those who received this information, we asked how useful it was; for those who did not, we asked how useful it would be. The questionnaire included open-ended items pertaining to information that providers needed and questions about provider and practice characteristics. The Web Survey Core at Memorial Sloan-Kettering Cancer Center (http://www.mskcc.org/mskcc/html/ 90103.cfm) implemented the online questionnaire via a secure and private platform. All data from the survey were received anonymously by Memorial Sloan-Kettering Cancer Center for analysis.

\section{Analyses}

We used descriptive analyses to report preferences and information needs. Participants with missing data were excluded on a question-by-question basis, and those participants missing more than 50\% of all responses were excluded from all analyses. For brevity, we presented only the percentage of respondents who reported each topic was very important to know and the percentage of respondents
Table 1. Demographic and Practice Characteristics of Study Sample ( $=156)$

\begin{tabular}{lc}
\hline & No. (\%) \\
\hline Practice-based research network & \\
$\quad$ Minnesota Academy of Family Practice & $43(28)$ \\
Penn State Ambulatory Research Network & $55(35)$ \\
Research Involving Outpatient Settings & $58(37)$ \\
$\quad$ Network & \\
Male Gender & $90(58)$ \\
Profession & \\
Physician & \\
$\quad$ Family medicine & $115(74)$ \\
$\quad$ Internal medicine* & $20(13)$ \\
$\quad$ No board certification reported & $2(1)$ \\
$\quad$ Nurse practitioner & $13(8)$ \\
Physician assistant & $6(4)$ \\
Electronic medical records used in practice & $134(86)$ \\
\hline & Mean (SD) \\
\hline Age (years) & $50(9)$ \\
Year training completed & $1989(10)$ \\
Cancer patients ${ }^{\dagger}$ seen during last year & $20(30)$ \\
Colorectal cancer patients ${ }^{\dagger}$ seen during last year & $3(4)$ \\
Survivors ${ }^{\dagger}$ of any cancer seen during last year & $44(67)$ \\
\hline & $6(9)$ \\
\hline & \\
\hline &
\end{tabular}

*One family physician was also board certified in internal medicine.

t"Patient" refers to people currently undergoing treatment. "Survivor" refers to those who completed treatment.

who felt they typically do not have enough information about the topic. We categorized physician specialty based on reported board certification. Physicians who reported multiple specialties were conservatively categorized as belonging to the more common specialty. Responses to open-ended items were grouped into categories and reported descriptively.

\section{Results \\ Sample}

Of the 409 PCPs who were invited to participate, 191 logged into the survey (47\%). Seventeen participants subsequently were found to be ineligible, and 18 participants were excluded because they completed less than $50 \%$ of the survey, resulting in 156 participants in the analytic sample (Table 1). One hundred thirty-seven participants (88\%) were physicians; $73 \%$ of physicians were family physicians. Because of the high proportion of family 
physicians, we compared their characteristics with those of the remaining respondents as a group. Family physicians were more likely to be men, were older, and completed training earlier than the remainder of the sample (data not shown). The distribution of provider types in our sample was not statistically different from that of the 3 networks, and we were unable to compare other demographic characteristics of our sample to the 3 networks. The mean reported number of CRC patients and survivors (ie, those who completed treatment) seen by respondents during the past year was 2.8 (standard deviation, 4.40) and 5.5 (standard deviation, 8.89), respectively.

\section{Importance of Topics in IOM Framework}

We categorized the 45 topics included in the IOM framework as patient-specific $(\mathrm{n}=34)$ or general $(\mathrm{n}=11)$, as shown in Tables 2 and 3. Across the 34 patient-specific topics, 71\% (24) were deemed very important to know by at least $50 \%$ of respondents (Table 2). Cancer characteristics (site, stage, grade, and pathology) were deemed important by the majority of participants $(60 \%-92 \%)$. Similarly, details about treatment (surgery, chemotherapy, and radiation) were deemed very important by at least 50\% of participants, except for the date of completion of chemotherapy, the name and dose of chemotherapy drugs, and the dose of radiation. A substantial minority $(37 \%-44 \%)$ indicated that information about other treatments provided, such as nutritional and psychosocial services, were very important to know. Ninety-eight percent of respondents felt that knowing whether the oncologist intended to monitor for recurrence and second CRCs was very important, and $90 \%$ reported that knowing whether the oncology provider intended to monitor for cancer at other sites (eg, subsequent breast cancer) was very important. Twenty-four of the 36 patient-specific topics (67\%) were deemed important or very important by $95 \%$ of respondents or more. Only 2 topics were considered unimportant by more than $20 \%$ of respondents: dose of chemotherapy (48\%) and dose of radiation (36\%) (data not shown).

For the 11 topics that are generalizable to all CRC survivors, at least $64 \%$ of respondents endorsed each topic as very important (Table 3). Ninety-eight percent felt knowing the schedule of recommended CRC surveillance was very important, and $98 \%$ felt that knowing increased risks for second CRCs, other cancers, and other diseases was very important. Fewer than $2 \%$ of respondents deemed each of the 11 topics unimportant. For each patient-specific or more generalized topic for which fewer than half of respondents deemed the topic very important, between $50 \%$ and $97 \%$ of respondents deemed the topic either somewhat important or very important (data not shown).

\section{Need for Information about Topics in the IOM Framework}

For patient-specific information, a substantial proportion of respondents reported typically not receiving enough information about their patient's diagnosis and treatment across all categories. The most widely endorsed topics for which respondents needed more information were knowing the reason for terminating chemotherapy (60\%), whether there were any problems with chemotherapy (67\%) or radiation therapy $(60 \%)$, and whether complementary services were provided during treatment, including psychosocial (66\%), nutritional (66\%), and other $(63 \%)$ supportive services. Seventy percent felt they typically did not have enough information about whether the oncologist intended to monitor the patient for cancers at other sites. A substantial minority of PCPs reported not having enough information about key clinical aspects of a cancer diagnosis, such as stage $(40 \%)$ and grade (44\%). Fewer than $5 \%$ of respondents felt they had too much information about each topic, with the exception of dose of chemotherapy and dose of radiation, for which $5 \%$ and $6 \%$ of respondents, respectively, felt they had too much information (data not shown).

There was a broader consensus that providers typically do not have enough information about more general issues affecting CRC survivors (ie, information that does not pertain to individual patients). At least half of all respondents reported needing more information about each general topic. Eighty-three percent typically wanted more information about genetic counseling and testing to identify high-risk individuals, whereas $78 \%$ typically needed more information about increased risks for second CRCs, other cancers, and other diseases. None of the respondents felt they had received too much information about CRC survivorship issues. 


\begin{tabular}{|c|c|c|}
\hline Topic* & $\begin{array}{l}\text { Very Important } \\
\text { To Know }\end{array}$ & $\begin{array}{l}\text { Not Enough } \\
\text { Information }\end{array}$ \\
\hline \multicolumn{3}{|l|}{ Diagnosis } \\
\hline Stage of the patient's disease & $143(92)$ & $63(40)$ \\
\hline Grade of the patient's disease & $122(78)$ & $68(44)$ \\
\hline Site of the patient's disease (colon or rectum) & $113(73)$ & $34(22)$ \\
\hline Relevant pathology of the patient's disease & $104(67)$ & $64(42)$ \\
\hline Where the patient received treatment & $93(60)$ & $38(24)$ \\
\hline Method of diagnosis & $76(49)$ & $36(23)$ \\
\hline \multicolumn{3}{|l|}{ Surgery } \\
\hline Whether patient had surgery & $144(92)$ & $15(10)$ \\
\hline Any lingering effects of surgery & $140(90)$ & $84(55)$ \\
\hline What the patient's anatomy is after surgery & $126(81)$ & $97(63)$ \\
\hline If there were surgical complications & $108(69)$ & $87(56)$ \\
\hline Date of the patient's surgery & $89(57)$ & $32(21)$ \\
\hline \multicolumn{3}{|l|}{ Chemotherapy } \\
\hline Whether patient had chemotherapy & $147(94)$ & $28(18)$ \\
\hline Reason for terminating chemotherapy & $123(79)$ & $93(60)$ \\
\hline Whether there were problems with chemotherapy & $120(77)$ & $104(68)$ \\
\hline Contact information for the doctor who administered chemotherapy & $96(62)$ & $66(42)$ \\
\hline Name of each chemotherapy drug administered & $56(36)$ & $67(43)$ \\
\hline Dates each regimen of chemotherapy was completed & $43(28)$ & $73(47)$ \\
\hline Dose of each chemotherapy drug administered & $8(5)$ & $71(46)$ \\
\hline \multicolumn{3}{|l|}{ Radiation } \\
\hline Whether patient had radiation therapy & $146(94)$ & $26(17)$ \\
\hline Whether there were problems with radiation therapy & $128(82)$ & $93(60)$ \\
\hline Reason for terminating radiation therapy & $111(72)$ & $87(56)$ \\
\hline Location where radiation was administered & $97(62)$ & $69(45)$ \\
\hline Contact information for the doctor who administered radiation therapy & $86(55)$ & $62(40)$ \\
\hline Date radiation therapy was completed & $85(54)$ & $61(39)$ \\
\hline Dose of radiation & $25(16)$ & $64(41)$ \\
\hline \multicolumn{3}{|l|}{ Other aspects of treatment } \\
\hline Whether patient was hospitalized for complications during treatment & $109(70)$ & $76(49)$ \\
\hline Whether psychosocial services were provided during treatment & $69(44)$ & $103(66)$ \\
\hline Whether patient was in a clinical trial & $63(40)$ & $87(56)$ \\
\hline Whether other supportive services were provided during treatment & $59(38)$ & $99(63)$ \\
\hline Whether nutritional services were provided during treatment & $58(37)$ & $103(66)$ \\
\hline \multicolumn{3}{|l|}{ Coordination of care } \\
\hline $\begin{array}{l}\text { Whether cancer care provider(s) intend(s) to monitor the patient for recurrences and } \\
\text { second primaries }\end{array}$ & $153(98)$ & $90(58)$ \\
\hline Whether cancer care provider(s) intend(s) to monitor the patient for cancers at other sites & $141(90)$ & $109(71)$ \\
\hline \multicolumn{3}{|l|}{ Medical reports } \\
\hline Pathology report & $106(68)$ & $71(46)$ \\
\hline Operative report & $73(47)$ & $62(40)$ \\
\hline
\end{tabular}

Values provided as $\mathrm{n}(\%)$.

*Adapted from Institute of Medicine Report. ${ }^{1}$

\section{Additional Topics of Importance}

For the open-ended items asking respondents to report additional needed information, the most commonly listed topics were the impact of the cancer on the family and psychological status of the patient; each topic was mentioned 17 times. Also commonly reported as lacking were patient-specific information about prognosis $(9$ comments) and comorbidities (7 comments). Providers 


\begin{tabular}{|c|c|c|}
\hline Topic* $^{*}$ & $\begin{array}{l}\text { Very Important } \\
\text { to Know }\end{array}$ & $\begin{array}{l}\text { Not Enough } \\
\text { Information }\end{array}$ \\
\hline Any increased risks for second colorectal cancers, other cancers, and other diseases & $153(98)$ & $122(78)$ \\
\hline The schedule of recommended colorectal cancer surveillance & $153(98)$ & $79(51)$ \\
\hline Possible signs of recurrence and second tumors & $145(93)$ & $93(60)$ \\
\hline The schedule of recommended screenings for noncolorectal cancers & $139(89)$ & $85(54)$ \\
\hline $\begin{array}{l}\text { Chemoprevention strategies for secondary prevention (eg, tamoxifen in women at high risk for } \\
\text { breast cancer) }\end{array}$ & $135(87)$ & $112(72)$ \\
\hline The possible long-term risks and complications from radiation therapy & $135(87)$ & $104(67)$ \\
\hline The possible long-term risks and complications from chemotherapy & $131(85)$ & $114(73)$ \\
\hline Other types of follow-up care providers that may be needed (eg, rehabilitation, fertility, psychology) & $124(79)$ & $111(71)$ \\
\hline $\begin{array}{l}\text { Genetic counseling and testing to identify high-risk individuals who could benefit from more } \\
\text { comprehensive cancer surveillance }\end{array}$ & $122(78)$ & $129(83)$ \\
\hline $\begin{array}{l}\text { Possible effects of cancer on marital/partner relationship, sexual functioning, work, parenting, and } \\
\text { future needs for psychosocial support }\end{array}$ & $117(75)$ & $99(63)$ \\
\hline Support groups and other resources for colorectal cancer survivors & $100(64)$ & $105(67)$ \\
\hline
\end{tabular}

Values provided as n (\%). Total number of respondents does not always equal 156 due to missing data.

*Adapted from Institute of Medicine Report. ${ }^{1}$

also lacked information about patients' practical concerns, including financial, legal, and transportation issues (11 comments).

\section{Preference for Format}

Of respondents, $83 \%$ reported that a printed survivorship care plan would be acceptable, a higher percentage than those who reported that receiving this information via web site, E-mail, or conversation with the oncology provider would be acceptable (Table 4). In response to open-ended questions about additional acceptable formats for survivorship care plans, 19 respondents volunteered that they would prefer the information in an electronic document that

Table 4. Preferences for Format and Delivery of Survivorship Care Plan

Participants Who Would Like This

$\begin{array}{lr}\text { Format } & \\ \text { Printed document } & 129(83) \\ \text { Website } & 39(25) \\ \text { E-mail } & 44(28) \\ \text { Conversation with cancer care provider } & 50(32) \\ \text { Delivery } & \\ \text { From the patient at an office visit } & 32(21) \\ \text { Directly from the cancer care } & 153(98) \\ \text { provider's office } & \end{array}$

Values provided as n (\%). Percentages do not add to 100 because respondents could select multiple formats or styles of delivery. would become integrated into the electronic medical record.

\section{Past Receipt and Usefulness}

Although the vast majority of respondents reported having ever received a summary of diagnosis or a summary of treatment for their patients who completed treatment for CRC $(86 \%$ and $89 \%$, respectively), a minority reported having ever received recommendations for ongoing primary care or information about what aspects of care the PCP and oncology provider are responsible for $30 \%$ and $20 \%$, respectively) (Table 5). Across these categories (summary of diagnosis, summary of treatment, recommendations for ongoing primary care, what aspects of care the PCP and oncology provider are responsible for), more than three quarters of those who had ever received information within each category found it useful $(77 \%-$ $81 \%$ ), and almost all respondents who never received this information reported that they would find it useful $(96 \%-100 \%)$. Nearly all respondents would like to receive a summary of the diagnosis (100\%), a summary of treatment (99\%), recommendations for ongoing care the patient should receive from the PCP (96\%), and information from the patient's cancer care provider about what aspects of care after treatment the PCP and the cancer care provider are each responsible for $(97 \%)$. 
Table 5. Primary Care Physicians' Perspectives Regarding Receipt and Usefulness of Information about Colorectal Cancer Survivors

\begin{tabular}{lccrr}
\hline Component of Survivorship Care Plan & N & $\begin{array}{c}\text { Ever Received } \\
\text { Component (Yes) }\end{array}$ & $\begin{array}{c}\text { Component Was } \\
\text { Extremely Useful }^{*}\end{array}$ & $\begin{array}{c}\text { Component Was } \\
\text { Somewhat Useful* }\end{array}$ \\
\hline Summary of diagnosis & 156 & $130(86)$ & $99(76)$ & $30(23)$ \\
Summary of treatment & 155 & $133(86)$ & $102(77)$ & $30(23)$ \\
Recommendations for ongoing primary care & 156 & $45(29)$ & $36(80)$ & $9(20)$ \\
$\begin{array}{l}\text { Information on what aspects of care PCP and } \\
\quad \text { cancer care providers are responsible for }\end{array}$ & 156 & $31(20)$ & $25(81)$ & $6(19)$ \\
\hline
\end{tabular}

Values provided as $\mathrm{n}(\%)$.

${ }^{*}$ Of those who ever did receive the component.

\section{Discussion}

We identified informational needs of PCPs who care for CRC survivors. When presented with 45 topics included in survivorship care plans, PCPs generally found them important but lacking when caring for CRC survivors. More than three quarters of the topics were deemed very important by at least half of participants, and few topics were deemed unimportant, suggesting that the IOM framework includes information that is critical to PCPs.

In survey studies of PCPs, PCPs typically have reported some discomfort when taking on the care of cancer survivors, either in the capacity of shared care with oncology providers or as sole providers of care after treatment. ${ }^{1-14}$ This may result from limited communication with oncology providers about patients' treatment. ${ }^{13}$ Our study found that providers rarely had complete information about CRC survivors' diagnosis and treatment, a problem that PCPs have reported in other studies (although sometimes to a lesser degree). ${ }^{11,15}$ Furthermore, most providers in our study valued communication regarding which specialty should assume responsibility for specific aspects of treatment, but only one-fifth ever received information delineating specific aspects of care between the PCP and the oncology provider.

PCPs previously have noted a lack of training about survivorship issues. ${ }^{11}$ Providers in our study reported a need for information about multiple facets of CRC follow-up. Although guidelines for CRC survivorship care are put forth by both the American Society of Clinical Oncology and the National Comprehensive Cancer Network, they are limited in scope, focusing on monitoring for recurrences and second CRCs and not on addressing medical and psychological late effects. ${ }^{16,17}$ They also are not directly disseminated to PCPs, who may not keep abreast of cancer society guidelines. Indeed, previous studies of PCPs have found limited awareness of guidelines and other information to inform follow-up care for cancer survivors. ${ }^{11,13}$

The use of survivorship care plans may ameliorate both poor communication and limited dissemination of survivorship information. Although survivorship care plans were proposed in 2006, fewer than a third of study participants ever received written recommendations for ongoing care, and fewer than a quarter ever received information about what aspects of care PCP and cancer care providers are responsible for. These are key elements of survivorship care plans, and our study demonstrates a critical gap between the IOM recommendations and the actual practice of survivorship care. This gap has been described elsewhere, and implementation of survivorship care plans lags behind recommendations. ${ }^{18}$

Respondents who received written recommendations for ongoing care and descriptions of responsibilities of each provider generally found this information useful. Furthermore, explicit coordination of care with regard to monitoring for CRC recurrence was deemed very important by $98 \%$ of respondents. Of those who never received information in survivorship care plans, nearly all reported that it would be useful. Previous studies have found that PCPs are receptive to survivorship care plans as tools to improve coordinated care for cancer survivors. ${ }^{1-12,15,18-20}$

Notably, a small proportion of providers in our study reported that the name and dose of chemotherapy drugs and the dose of radiation were very important, although a substantial proportion of respondents $(41 \%-46 \%)$ felt they did not have enough information about these topics. This discrepancy may be 
explained by at least half of respondents finding these topics at least somewhat important (data not shown). These treatment details may be the most relevant risk factors predicting the occurrence of important late effects. However, reporting treatment may be the most burdensome part of completing a survivorship care plan. A simplified strategy for presenting information in survivorship care plans would entail limiting the presentation of treatment details (which PCPs find less important than other information) but providing clear guidance about how to prevent, detect, and manage the late effects of treatment.

Our study had a limited response rate, although it is similar to the response rate (37\%) achieved in a similar Internet-based survey of providers within PBRNs. ${ }^{21}$ In that study, an option of a mailed, paperbased survey improved response rates, but we opted to limit our survey to Internet-based administration to reduce network and clinician burden. It is possible that those who did not respond to our Internet-based survey but would have responded to a paper-based survey have different informational preferences, especially regarding the format when receiving information, than our sample. More generally, it also is possible that our sample participants were more interested than nonresponders in the challenges of caring for CRC survivors or felt a stronger need for information, potentially biasing our results toward demonstrating greater informational needs. The widespread agreement across issues raised in this study suggests that, even if there were a bias, a pattern of strong needs and preferences for information would remain. This study was not powered to identify predictors of preferences for information, which may vary by provider characteristics, such as experience with CRC survivors. This survey relied on providers to recall their experiences and report estimates, and we were unable to verify responses. The characteristics of the PCPs at the 3 sites chosen for this study may not be generalizable to all PCPs. However, we have no reason to believe that participants were more or less informed about CRC or interested in receiving survivorship information than PCPs elsewhere.

Our study focused on the use of survivorship care plans as static documents communicating information from the oncologist to the PCP, as described in the IOM report. ${ }^{1}$ However, coordination may be enhanced with the use of dynamic survivorship care plans that oncologists update over the course of treatment and follow-up, thereby keeping PCPs informed while the patient is under the oncologist's care. ${ }^{22,23} \mathrm{At}$ the same time, PCPs may wish to inform the oncologist about changes in the survivor's health status, the provision of testing, or other general preventive measures. Future studies should examine whether a dynamic survivorship care plan would be useful and feasible for PCPs, CRC survivors, and oncologists.

This is the first published study of which we are aware that assesses the potential usefulness to PCPs of the IOM framework for survivorship care plans for CRC survivors. Our sample of PCPs, which includes physicians and nonphysician providers in academic and community settings in multiple distinct locations, represents a wide array of practitioners. Despite this diversity, there is widespread agreement that providers would appreciate and use the information in the IOM framework. There are deficiencies in communication about survivors' treatment history and specific gaps in knowledge about CRC survivorship, both of which should be addressed in survivorship care plans created for CRC survivors.

\section{Conclusions}

Findings from this study suggest that PCPs want comprehensive CRC survivorship information, but before calling for the development of lengthy CRC survivorship care plans, further research with oncologists must assess whether creating such detailed documents is feasible and deemed an important use of clinical resources. Our study still provides a strong evidence base for the creation of a CRC survivorship care plan that responds to the needs of PCPs. The development of a new CRC survivorship care plan will provide a basis for future research evaluating whether survivorship care plan use resolves deficiencies in care for CRC survivors. Specifically, studies need to address whether survivorship care plans facilitate coordination of care, improve quality of care, and help PCPs feel more comfortable in providing care to CRC survivors.

\section{References}

1. Hewitt M, Greenfield S, Stovall E. From cancer patient to cancer survivor: lost in transition. Washington, D.C.: Institute of Medicine and National 
Research Council; 2005. Available from: http:// www.nap.edu/openbook.php? isbn $=0309095956$.

2. Centers for Disease Control and Prevention (CDC). Cancer survivors-United States, 2007. MMWR Morb Mortal Wkly Rep. 2011;60:269-72.

3. American Cancer Society. Cancer facts and figures 2010. Available from: http://www.cancer.org/acs/ groups/content/@nho/documents/document/acspc024113.pdf. Accessed July 12, 2012.

4. Deimling GT, Bowman KF, Sterns S, Wagner LJ, Kahana B. Cancer-related health worries and psychological distress among older adult, long-term cancer survivors. Psychooncology 2006;15:306-20.

5. Denlinger C, Barsevick A. The challenges of colorectal cancer survivorship. J Natl Compr Canc Netw 2009;7:883-93.

6. Harrison SE, Watson EK, Ward AM, et al. Primary health and supportive care needs of long-term cancer survivors: a questionnaire survey. J Clin Oncol 2011; 29:2091-8.

7. Schneider EC, Malin JL, Kahn KL, Ko CY, Adams J, Epstein AM. Surviving colorectal cancer: patientreported symptoms 4 years after diagnosis. Cancer 2007;110:2075-82.

8. Earle CC, Neville BA. Under use of necessary care among cancer survivors. Cancer 2004;101:1712-9.

9. Snyder CF, Earle CC, Herbert RJ, Neville BA, Blackford AL, Frick KD. Preventive care for colorectal cancer survivors: a 5-year longitudinal study. J Clin Oncol 2008;26:1073-9.

10. Snyder CF, Earle CC, Herbert RJ, Neville BA, Blackford AL, Frick KD. Trends in follow-up and preventive care for colorectal cancer survivors. J Gen Intern Med 2008;23:254-9.

11. Bober SL, Recklitis CJ, Campbell EG, et al. Caring for cancer survivors: a survey of primary care physicians. Cancer 2009;115(Suppl 18):4409-18.

12. Del Giudice ME, Grunfeld E, Harvey BJ, Piliotis E, Verma S. Primary care physicians' views of routine follow-up care of cancer survivors. J Clin Oncol 2009;27:3338-45.

13. Nissen MJ, Beran MS, Lee MW, Mehta SR, Pine DA, Swenson KK. Views of primary care providers on follow-up care of cancer patients. Fam Med 2007; 39:477-82.

14. Potosky AL, Han PK, Rowland J, et al. Differences between primary care physicians' and oncologists' knowledge, attitudes and practices regarding the care of cancer survivors. J Gen Intern Med 2011;26: 1403-10.

15. Baravelli C, Krishnasamy M, Pezaro C, et al. The views of bowel cancer survivors and health care professionals regarding survivorship care plans and post treatment follow up. J Cancer Surviv 2009;3:99-108.

16. National Comprehensive Cancer Network . NCCN guidelines: NCCN Guidelines for detection, prevention, and risk reduction. Colorectal cancer screening.
Available from: http://www.nccn.org/professionals/ physician_gls/f_guidelines.asp\#detection. Accessed July 12, 2012.

17. Benson AB 3rd, Desch CE, Flynn PJ, et al. 2000 update of American Society of Clinical Oncology colorectal cancer surveillance guidelines. J Clin Oncol 2000;18:3586-8.

18. Salz T, Oeffinger K, McCabe M, Layne T, Bach P. Survivorship care plans in research and practice. CA Cancer J Clin 2012 Jan 12. Doi:10.3322/caac.20142. [Epub ahead of print].

19. Hewitt ME, Bamundo A, Day R, Harvey C. Perspectives on post-treatment cancer care: qualitative research with survivors, nurses, and physicians. J Clin Oncol 2007;25:2270-3.

20. Shalom MM, Hahn EE, Casillas J, Ganz PA. Do Survivorship care plans make a difference? A primary care provider perspective. J Oncol Pract 2011;7: 314-8.

21. Kroth PJ, McPherson L, Leverence R, et al. Combining web-based and mail surveys improves response rates: a PBRN study from PRIME Net. Ann Fam Med. 2009;7:245-8.

22. Earle CC. Failing to plan is planning to fail: improving the quality of care with survivorship care plans. J Clin Oncol 2006;24:5112-6.

23. Horning SJ. Follow-up of adult cancer survivors: new paradigms for survivorship care planning. Hematol Oncol Clin North Am 2008;22:201-10, v.

\section{Appendix: Survey}

Please note that the online version of this survey did not include question numbers. In the online version, skip patterns for the survey were automated; in this Appendix they are noted in brackets.

\section{Primary Care of Colorectal Cancer Survivors}

Thank you for agreeing to participate in our survey about the information primary care providers receive-and would like to receive-about the cancer survivors they care for in their clinical practice. We hope the information from this survey will improve communication about cancer care for cancer survivors. The survey should take about 10 to 15 minutes to complete.

As a thank you for your participation, you will receive a \$50 Amazon.com Gift Card via E-mail. When you are done, you will be asked to provide an E-mail address so that we can E-mail you the electronic gift certificate. You will receive your electronic gift certificate within 30 minutes. Please note: Your Amazon.com Gift Card will be in an email from $<$ name $>$, with the email ad- 
dress <email address $>$. If your email account uses a spam trap, either check you spam trap for this email or add this email address to you list of safe senders.

You may skip any questions you do not feel comfortable answering. Your responses will remain anonymous. When you finish the survey, your survey responses and a unique study ID will be sent electronically to our study team at Memorial Sloan-Kettering Cancer Center. We will not have access to your name, your clinical practice, or your work email address. The email address you provide at the end of this survey (for payment purposes) can be any email address you choose - you can use a personal email account or a work email account. This email address will not be associated with your responses to the survey. This is to ensure your privacy.

If you have any questions about this survey, please call $<\mathrm{PI}>$ at $<$ phone $>$.

Please answer the following questions to see if you are eligible for the study.

1. Do you provide primary care in your practice? $\circ$ Yes

○ No [Sorry, you are not eligible to participate in this survey. Thank you for your time and interest.]

2. During the last year, did you see any patients in your practice who had completed therapy for colon or rectal cancer at any point in their lives?

$\circ$ Yes

- No [Sorry, you are not eligible to participate in this survey. Thank you for your time and interest.]

- Don't remember [Sorry, you are not eligible to participate in this survey. Thank you for your time and interest.]

You are eligible for the survey. These first few questions are about your medical practice and your patients.

3. What is your profession?

○ Physician [Go to question 4.]

○ Nurse Practitioner [Go to question 6.]

○ Physician assistant [Go to question 7.]

4. Are you board certified in any of the following specialties? $\square$ Internal Medicine

$\square$ Geriatrics

$\square$ Family practice

$\square$ A medical subspecialty (please list):

5. In what year did you graduate from medical school?

[Go to question 8.]

6. In what year did you complete your nurse practitioner training?

[Go to question 8.]

7. In what year did you complete your physician assistant training? [Go to question 8.]

8. How old are you?

9. What is your gender?

o Male

○ Female

10. How many practitioners (MD, DO, NP, or $\mathrm{PA})$ are in your office?

11. In what zip code is your practice is located?

12. Does your practice use electronic health records?

$\circ$ Yes

$\circ$ No

13. Are there any oncologists or cancer specialists in your practice?

$\circ$ Yes

$\circ$ No

$\circ$ Don't know

14. During the last 12 months, how many patients who were currently undergoing 
treatment for any kind of cancer do you estimate that you cared for in your practice? Please count any patients who were undergoing cancer treatment for any part of the last 12 months.

15. How many of these patients had been diagnosed with colorectal cancer?

[If 0 patients, "Sorry, you are not eligible to participate in this survey. Thank you for your time and interest."]

16. During the last 12 months, how many individual patients who had completed active treatment for any kind of cancer do you estimate that you cared for in your practice? Please count any patients who had completed cancer treatment any time during or before the last 12 months.

\section{Topic 1: Diagnosis Summary}

When you see patients who have completed treatment for colon or rectal cancer and do not have active disease, how important is it for you to know:

\begin{tabular}{|c|c|c|c|c|}
\hline & $\begin{array}{c}\text { Not } \\
\text { Important }\end{array}$ & $\begin{array}{l}\text { Somewhat } \\
\text { Important }\end{array}$ & $\begin{array}{c}\text { Very } \\
\text { Important }\end{array}$ & Undecided \\
\hline $19 . \ldots$ the method of diagnosis & ○ & ○ & ○ & ○ \\
\hline $20 . \ldots$ where the patient received treatment & ○ & ○ & $\circ$ & ○ \\
\hline 21. ... the site of the patient's disease (colon or rectum) & ○ & ○ & ○ & ○ \\
\hline 22. ... the stage of the patient's disease & ○ & ○ & ○ & ○ \\
\hline $23 . .$. the grade of the patient's disease & ○ & ○ & ○ & ○ \\
\hline 24. ... the relevant pathology of the patient's disease & ○ & ○ & ○ & ○ \\
\hline
\end{tabular}

When you see patients who have completed treatment for colon or rectal cancer and do not have active disease, how much information do you typically have about:

\begin{tabular}{|c|c|c|c|c|}
\hline & $\begin{array}{l}\text { Not } \\
\text { Enough }\end{array}$ & $\begin{array}{l}\text { Just the } \\
\text { Right Amount }\end{array}$ & $\begin{array}{l}\text { Too } \\
\text { Much }\end{array}$ & $\begin{array}{l}\text { It Varies Too } \\
\text { Much To Say }\end{array}$ \\
\hline 25. ... the method of diagnosis & O & O & ○ & ○ \\
\hline 26. ... where the patient received treatment & O & O & O & O \\
\hline 27. ... the site of the patient's disease (colon or rectum) & O & ○ & O & ○ \\
\hline 28. ... the stage of the patient's disease & O & ○ & ○ & ○ \\
\hline 29. ... the grade of the patient's disease & ○ & O & ○ & ○ \\
\hline 30. ... the relevant pathology of the patient's disease & O & O & o & o \\
\hline
\end{tabular}

17. How many of these patients had been diagnosed with colorectal cancer?

18. Please think about your patients who have completed treatment for any kind of cancer and do not have active disease. For what percentage of these patients do you feel you have enough information to provide the best general medical care (for example, screening and health maintenance) for them?

The following questions are about the information you receive about your patients who have completed treatment for colon or rectal cancer and do not have active disease. We will ask you how important it is for you to have information about these patients and how much information you usually get about them.

There will be questions about 6 topics of medical information you get about your patients. 
Topic 2: Surgery

When you see patients who have completed treatment for colon or rectal cancer and do not have active disease, how important is it for you to know:

\begin{tabular}{|c|c|c|c|c|}
\hline & $\begin{array}{c}\text { Not } \\
\text { Important }\end{array}$ & $\begin{array}{l}\text { Somewhat } \\
\text { Important }\end{array}$ & $\begin{array}{c}\text { Very } \\
\text { Important }\end{array}$ & Undecided \\
\hline 31. ... whether the patient had surgery & 0 & ○ & o & ○ \\
\hline 32. ... the date of the patient's surgery & o & ○ & ○ & o \\
\hline 33. ... whether there were surgical complications & ○ & ० & ○ & o \\
\hline 34. ... what the patient's anatomy is after surgery & ○ & ○ & ० & ० \\
\hline $35 . \ldots$ whether there are lingering effects of surgery & 0 & 0 & 0 & o \\
\hline
\end{tabular}

When you see patients who have completed treatment for colon or rectal cancer and do not have active disease, how much information do you typically have about:

\begin{tabular}{|c|c|c|c|c|}
\hline & $\begin{array}{c}\text { Not } \\
\text { Enough }\end{array}$ & $\begin{array}{l}\text { Just the } \\
\text { Right Amount }\end{array}$ & $\begin{array}{l}\text { Too } \\
\text { Much }\end{array}$ & $\begin{array}{l}\text { It Varies Too } \\
\text { Much To Say }\end{array}$ \\
\hline 36. ... whether the patient had surgery & O & ○ & o & o \\
\hline $37 . .$. the date of the patient's surgery & O & ○ & ○ & o \\
\hline 38. ... if there were surgical complications & ० & ○ & $\circ$ & o \\
\hline 39. ... what the patient's anatomy is after surgery & ○ & ○ & ○ & ○ \\
\hline 40. ... whether there are lingering effects of surgery & 0 & o & 0 & 0 \\
\hline
\end{tabular}

\section{Topic 3: Chemotherapy}

When you see patients who have completed treatment for colon or rectal cancer and do not have active disease, how important is it for you to know:

$\begin{array}{cccc}\text { Not } & \text { Somewhat } & \text { Very } & \\ \text { Important } & \text { Important } & \text { Important } & \text { Undecided }\end{array}$

41. ... whether the patient had chemotherapy

42. ... the dates each regimen of chemotherapy was completed

43. ... the name of each chemotherapy drug administered

44. ... the dose of each chemotherapy drug administered

45. ... the possible long-term risks and complications from chemotherapy

46. ... the contact information for the doctor who administered chemotherapy

47. ... the reason for terminating chemotherapy

48. ... whether there were problems with chemotherapy

$\begin{array}{ll}0 & 0 \\ 0 & 0 \\ 0 & 0 \\ 0 & 0 \\ 0 & 0 \\ 0 & 0 \\ 0 & 0 \\ 0 & 0\end{array}$

When you see patients who have completed treatment for colon or rectal cancer and do not have active disease, how much information do you typically have about:

\begin{tabular}{|c|c|c|c|c|}
\hline & $\begin{array}{c}\text { Not } \\
\text { Enough }\end{array}$ & $\begin{array}{l}\text { Just the } \\
\text { Right Amount }\end{array}$ & $\begin{array}{l}\text { Too } \\
\text { Much }\end{array}$ & $\begin{array}{l}\text { It Varies Too } \\
\text { Much To Say }\end{array}$ \\
\hline 49.... whether the patient had chemotherapy & $\circ$ & $\circ$ & $\circ$ & $\circ$ \\
\hline $50 . .$. the dates each regimen of chemotherapy was completed & ○ & $\circ$ & ○ & $\circ$ \\
\hline 51.... the name of each chemotherapy drug administered & ○ & $\circ$ & ○ & ○ \\
\hline 52. ... the dose of each chemotherapy drug administered & $\circ$ & $\circ$ & ○ & $\circ$ \\
\hline 53. ... the possible long-term risks and complications from chemotherapy & ○ & $\circ$ & ○ & ○ \\
\hline 54. ... the contact information for the doctor who administered chemotherapy & ○ & $\circ$ & ○ & $\circ$ \\
\hline $55 . \ldots$ the reason for terminating chemotherapy & $\circ$ & $\circ$ & $\circ$ & $\circ$ \\
\hline 56. ... whether there were problems with chemotherapy & ○ & ○ & ○ & ○ \\
\hline
\end{tabular}


Topic 4: Radiation Therapy

When you see patients who have completed treatment for colon or rectal cancer and do not have active disease, how important is it for you to know:

\begin{tabular}{|c|c|c|c|c|}
\hline & $\begin{array}{c}\text { Not } \\
\text { Important }\end{array}$ & $\begin{array}{l}\text { Somewhat } \\
\text { Important }\end{array}$ & $\begin{array}{c}\text { Very } \\
\text { Important }\end{array}$ & Undecided \\
\hline 57. ... whether the patient had radiation therapy & ○ & ○ & ○ & ○ \\
\hline 58. ... the date radiation therapy was completed & ○ & ○ & ○ & o \\
\hline $59 . .$. the location where radiation was administered & ○ & ○ & $\circ$ & ○ \\
\hline $60 . .$. the dose of radiation & ○ & ○ & ○ & ० \\
\hline 61. ... the contact information for the doctor who administered radiation therapy & ○ & o & ○ & o \\
\hline 62. ... the possible long-term risks and complications from radiation therapy & o & ○ & ○ & ○ \\
\hline 63. ... the reason for terminating radiation therapy & ○ & ○ & ○ & o \\
\hline 64. ... whether there were problems with radiation therapy & 0 & 0 & 0 & 0 \\
\hline
\end{tabular}

When you see patients who have completed treatment for colon or rectal cancer and do not have active disease, how much information do you typically have about:

\begin{tabular}{|c|c|c|c|c|}
\hline & $\begin{array}{l}\text { Not } \\
\text { Enough }\end{array}$ & $\begin{array}{l}\text { Just the } \\
\text { Right Amount }\end{array}$ & $\begin{array}{l}\text { Too } \\
\text { Much }\end{array}$ & $\begin{array}{c}\text { It Varies } \\
\text { Too Much To Say }\end{array}$ \\
\hline 65.... whether the patient had radiation therapy & ○ & o & O & ○ \\
\hline 66. ... the date radiation therapy was completed & ○ & ○ & ○ & ○ \\
\hline 67. ... the location where radiation was administered & ० & ○ & ○ & ० \\
\hline $68 . .$. the dose of radiation & 0 & o & o & ○ \\
\hline $\begin{array}{l}\text { 69. ... the contact information for the doctor who administered radiation } \\
\text { therapy }\end{array}$ & ○ & o & ○ & ○ \\
\hline $\begin{array}{l}\text { 70. ... the possible long-term risks and complications from radiation } \\
\text { therapy }\end{array}$ & ○ & o & ○ & ○ \\
\hline $71 . \ldots$ the reason for terminating radiation therapy & 0 & o & o & o \\
\hline 72. ... whether there were problems with radiation therapy & 0 & 0 & 0 & 0 \\
\hline
\end{tabular}

\section{Topic 5: Other Aspects of Treatment}

When you see patients who have completed treatment for colon or rectal cancer and do not have active disease, how important is it for you to know:

\begin{tabular}{|c|c|c|c|c|}
\hline & $\begin{array}{c}\text { Not } \\
\text { Important }\end{array}$ & $\begin{array}{l}\text { Somewhat } \\
\text { Important }\end{array}$ & $\begin{array}{c}\text { Very } \\
\text { Important }\end{array}$ & Undecided \\
\hline 73. ... whether the patient was in a clinical trial & ○ & ○ & ○ & ○ \\
\hline 74. ... if the patient was hospitalized for complications during treatment & ○ & ○ & ○ & ० \\
\hline 75. ... whether psychosocial services were provided during treatment & ○ & ○ & ○ & ○ \\
\hline 76. ... whether nutritional services were provided during treatment & o & o & o & o \\
\hline 77. ... whether other supportive services were provided during treatment & ○ & ○ & ○ & ○ \\
\hline
\end{tabular}

When you see patients who have completed treatment for colon or rectal cancer and do not have active disease, how much information do you typically have about:

\begin{tabular}{|c|c|c|c|c|}
\hline & $\begin{array}{l}\text { Not } \\
\text { Enough }\end{array}$ & $\begin{array}{l}\text { Just the } \\
\text { Right Amount }\end{array}$ & $\begin{array}{l}\text { Too } \\
\text { Much }\end{array}$ & $\begin{array}{c}\text { It Varies } \\
\text { Too Much To Say }\end{array}$ \\
\hline 78. ... whether the patient was in a clinical trial & O & ○ & O & O \\
\hline 79. ... whether the patient was hospitalized for complications during treatment & O & O & O & O \\
\hline 80. ... whether psychosocial services were provided during treatment & O & O & O & O \\
\hline 81. ... whether nutritional services were provided during treatment & O & O & O & O \\
\hline 82. ... whether other supportive services were provided during treatment & O & O & ○ & 0 \\
\hline
\end{tabular}


Topic 6: Continuity of Care

When you see patients who have completed treatment for colon or rectal cancer and do not have active disease, how important is it for you to know:

\begin{tabular}{|c|c|c|c|c|}
\hline & $\begin{array}{l}\text { Not } \\
\text { Important }\end{array}$ & $\begin{array}{l}\text { Somewhat } \\
\text { Important }\end{array}$ & $\begin{array}{c}\text { Very } \\
\text { Important }\end{array}$ & Undecided \\
\hline $\begin{array}{l}\text { 83. ... whether the cancer care provider(s) intend(s) to monitor } \\
\text { the patient for recurrence and second primaries }\end{array}$ & o & o & O & o \\
\hline $\begin{array}{l}\text { 84. ... whether the cancer care provider(s) intend(s) } \\
\text { to monitor the patient for cancers at other sites }\end{array}$ & ○ & ○ & O & ○ \\
\hline
\end{tabular}

When you see patients who have completed treatment for colon or rectal cancer and do not have active disease, how much information do you typically have about:

\begin{tabular}{|c|c|c|c|c|}
\hline & $\begin{array}{l}\text { Not } \\
\text { Enough }\end{array}$ & $\begin{array}{l}\text { Just the } \\
\text { Right Amount }\end{array}$ & $\begin{array}{l}\text { Too } \\
\text { Much }\end{array}$ & $\begin{array}{l}\text { It Varies Too } \\
\text { Much To Say }\end{array}$ \\
\hline $\begin{array}{l}\text { 83. ... whether the cancer care provider(s) intend(s) } \\
\text { to monitor the patient for recurrence and second primaries }\end{array}$ & 0 & 0 & 0 & 0 \\
\hline $\begin{array}{l}\text { 84. ... whether the cancer care provider(s) intend(s) } \\
\text { to monitor the patient for cancers at other sites }\end{array}$ & 0 & 0 & 0 & 0 \\
\hline
\end{tabular}

Please tell us about any other topics that are important to you that we did not ask about. These topics can be about diagnosis, surgery, chemotherapy, radiation therapy, other aspects of treatment, continuity of care, or any other aspect of patient care.

When you see patients who have completed treatment for colon or rectal cancer and do not have active disease,

how much information do you typically have about this topic?

Please list any topics that are important to you below

\begin{tabular}{|c|c|c|c|}
\hline Not Enough & $\begin{array}{l}\text { Just the } \\
\text { Right Amount }\end{array}$ & Too Much & $\begin{array}{l}\text { It Varies Too } \\
\text { Much To Say }\end{array}$ \\
\hline
\end{tabular}

\begin{tabular}{l}
85. \\
86. \\
87. \\
88. \\
89. \\
\hline
\end{tabular}

$\circ$
$\circ$
$\circ$
$\circ$
$\circ$

$\begin{array}{lll}\circ & 0 & 0 \\ \circ & 0 & 0 \\ \circ & 0 & 0 \\ \circ & 0 & 0 \\ \circ & 0 & 0\end{array}$

This set of questions is about information you receive about your patients who have had colon or rectal cancer.

\section{Topic 7: Medical Reports}

When you see patients who have completed treatment for colon or rectal cancer and do NOT have active disease, how important is it for you to have:

\begin{tabular}{lcccc}
\hline & $\begin{array}{c}\text { Not } \\
\text { Important }\end{array}$ & $\begin{array}{c}\text { Somewhat } \\
\text { Important }\end{array}$ & $\begin{array}{c}\text { Very } \\
\text { Important }\end{array}$ & Undecided \\
\hline $90 . \ldots$ the operative report & 0 & 0 & 0 & 0 \\
$91 . .$. the pathology report & 0 & 0 & 0 & 0 \\
\hline
\end{tabular}

When you see patients who have completed treatment for colon or rectal cancer and do NOT have active disease, how much information do you typically have about:

\begin{tabular}{lccc}
\hline & $\begin{array}{c}\text { Not } \\
\text { Enough }\end{array}$ & $\begin{array}{c}\text { Just the } \\
\text { Right Amount }\end{array}$ & $\begin{array}{c}\text { Too } \\
\text { Much }\end{array}$ \\
$92 . .$. the operative report & 0 & 0 & 0 \\
$93 . .$. the pathology report & 0 & 0 & 0 \\
\hline
\end{tabular}

This set of questions is about general knowledge about treating patients who have had colon or rectal cancer. 
Topic 8: General Knowledge

For patients who have completed treatment for colon or rectal cancer and do not have active disease, how important is it for you to know about:

\begin{tabular}{|c|c|c|c|c|}
\hline & $\begin{array}{l}\text { Not } \\
\text { Important }\end{array}$ & $\begin{array}{l}\text { Somewhat } \\
\text { Important }\end{array}$ & $\begin{array}{c}\text { Very } \\
\text { Important }\end{array}$ & Undecided \\
\hline 94. ... the schedule of recommended colorectal cancer surveillance & ○ & O & ○ & o \\
\hline 95. ... the schedule of recommended screening for noncolorectal cancers & o & ○ & ○ & ○ \\
\hline $\begin{array}{l}\text { 96. ... any increased risks for second colorectal cancers, other cancer, } \\
\text { and other diseases }\end{array}$ & O & ○ & ○ & ○ \\
\hline 97. ... possible signs of recurrence and second tumors & ○ & ○ & ○ & ○ \\
\hline $\begin{array}{l}\text { 98. ... possible effects of cancer on marital/partner relationship, sexual } \\
\text { functioning, work, parenting, and future needs for psychosocial support }\end{array}$ & 0 & ○ & ○ & ○ \\
\hline $\begin{array}{l}\text { 99. ... genetic counseling and testing to identify high-risk individuals who } \\
\text { could benefit from more comprehensive cancer surveillance }\end{array}$ & o & O & O & O \\
\hline $\begin{array}{l}\text { 100. ... chemoprevention strategies for secondary prevention } \\
\text { (eg, tamoxifen in women at high risk for breast cancer) }\end{array}$ & o & 0 & O & 0 \\
\hline $\begin{array}{l}\text { 101. ... other types of follow-up care providers that may be needed } \\
\text { (eg, rehabilitation, fertility, psychology) }\end{array}$ & 0 & 0 & 0 & 0 \\
\hline 102. ... support groups and other resources for colorectal cancer survivors & 0 & 0 & 0 & 0 \\
\hline
\end{tabular}

For patients who have completed treatment for colon or rectal cancer and do not have active disease, how much do you know about:

\begin{tabular}{|c|c|c|c|}
\hline & $\begin{array}{l}\text { Not } \\
\text { Enough }\end{array}$ & Enough & $\begin{array}{c}\text { It Varies } \\
\text { Too Much To Say }\end{array}$ \\
\hline 103. ... the schedule of recommended colorectal cancer surveillance & ○ & ○ & ○ \\
\hline 104. ... the schedule of recommended screening for noncolorectal cancers & $\circ$ & $\circ$ & ○ \\
\hline $\begin{array}{l}\text { 105. ... any increased risks for second colorectal cancers, other cancer, } \\
\text { and other diseases }\end{array}$ & ○ & ○ & ○ \\
\hline 106. ... possible signs of recurrence and second tumors & ○ & ○ & ○ \\
\hline $\begin{array}{l}\text { 107. ... possible effects of cancer on marital/partner relationship, sexual } \\
\text { functioning, work, parenting, and future needs for psychosocial support }\end{array}$ & ○ & ○ & ○ \\
\hline $\begin{array}{l}\text { 108. ... genetic counseling and testing to identify high-risk individuals } \\
\text { who could benefit from more comprehensive cancer surveillance }\end{array}$ & ○ & ○ & ○ \\
\hline $\begin{array}{l}\text { 109. ... chemoprevention strategies for secondary prevention } \\
\text { (eg, tamoxifen in women at high risk for breast cancer) }\end{array}$ & ○ & $\circ$ & ○ \\
\hline $\begin{array}{l}\text { 110. ... other types of follow-up care providers that may be needed } \\
\text { (eg, rehabilitation, fertility, psychology) }\end{array}$ & $\circ$ & $\circ$ & ○ \\
\hline 111. ... support groups and other resources for colorectal cancer survivors & ○ & ○ & ○ \\
\hline
\end{tabular}

Please tell us about any other area of general knowledge that is important to you that we did not ask about. These topics can be about any aspect of care for patients who have completed treatment for colon or rectal cancer.

\begin{tabular}{|c|c|c|c|}
\hline \multirow{2}{*}{$\begin{array}{l}\text { Please list below any areas of knowledge that are } \\
\text { important to you: }\end{array}$} & \multicolumn{3}{|c|}{ How much do you know about this area? } \\
\hline & Not Enough & Enough & It Varies Too Much To Say \\
\hline 112. & ○ & ○ & ० \\
\hline 113. & 0 & ० & o \\
\hline 114. & ○ & ○ & ○ \\
\hline 115 . & ○ & ० & ○ \\
\hline 116. & $\circ$ & o & o \\
\hline
\end{tabular}


The following questions are about written information you received about your patients who have had colon or rectal cancer. There are 4 topics of written information.

\section{Topic 1: Diagnosis Summary}

117. Have you ever received a report from a cancer care provider summarizing a patient's cancer diagnosis?

$\circ$ Yes [Go to question 118.]

○ No [Go to question 119.]

○ Don't remember [Go to question 119.]

118. How useful was it?

$\circ$ Extremely useful

○ Somewhat useful

O Not useful at all

o Don't remember

119. Would you like to receive a summary report of the cancer diagnosis for each patient?

$\circ$ Yes

$\circ$ Not sure

$\circ$ No

\section{Topic 2: Treatment Summary}

120. Have you ever received a report from a cancer care provider summarizing a patient's cancer treatment (such as surgery, chemotherapy, or radiation)?

$\circ$ Yes [Go to question 121.]

$\circ$ No [Go to question 122.]

○ Don't remember [Go to question 122.]

121. How useful was it?

○ Extremely useful

○ Somewhat useful

$\circ$ Not useful at all

$\circ$ Don't remember

122. Would you like to receive a summary report of the cancer treatment for each patient?

$\circ$ Yes

o Not sure

$\circ$ No

\section{Topic 3: Recommendations for Ongoing Care}

123. Have you ever received a summary of the ongoing care the patient should receive from their primary care provider?

- Yes [Go to question 124.]

○ No [Go to question 125.]

- Don't remember [Go to question 125.]

124. How useful was it?

$\circ$ Extremely useful

- Somewhat useful

o Not useful at all

o Don't remember

125. Would you like to receive a summary of recommended ongoing care for each patient?

$\circ$ Yes

○ Not sure

$\circ$ No

Topic 4: Written Information about Responsibilities for Care After Treatment

126. Have you ever received written information from a patient's cancer care provider about what aspects of post-treatment care you and the cancer care provider are each responsible for?

$\circ$ Yes [Go to question 127.]

- No [Go to question 128.]

$\circ$ Don't remember [Go to question 128.]

127. How useful was it?

○ Extremely useful

- Somewhat useful

○ Not useful at all

○ Don't remember

128. Would you like to have a written information from each patient's cancer care provider about what aspects of posttreatment care you and the cancer care provider are each responsible for?

$\circ$ Yes

o Not sure

$\circ$ No 
You indicated that you would like to receive some information about the diagnosis, treatment, or recommended care for each patient who finished active treatment for cancer.

The following questions are about your preferences for receiving this information about diagnosis, treatment, or recommended ongoing care for your patients who have completed treatment for any kind of cancer.

129. If you were to receive this information, what format would be most useful to you? (Please check all that apply.)

A printed document

$\square$ A link to a web site

$\square$ An E-mail

$\square$ A conversation with the cancer care provider

$\square$ Other (please describe)

130. How would you like to receive this information? (Please check all that apply.) $\square$ From the patient at an office visit

$\square$ Directly from the cancer care provider's office

$\square$ Other (please describe)

Thank you for your participation! Please enter your email address below so that we can email you a $\$ 50$ gift certificate to Amazon.com. You will receive your gift certificate in an email from $<$ name redacted $>$.

131. E-mail address:

132. Please verify E-mail address:

Note: you do not need to use the same E-mail address to which your invitation was mailed. Please make sure you can receive eE-mail at the address you entered above. Your Amazon.com gift card will be in an eE-mail from $<$ name redacted $>$, with the E-mail address < address redacted $>$. If your E-mail account uses a spam trap, either check you spam trap for this E-mail or add this E-mail address to your list of safe senders.

Thanks for taking the survey. We hope this will help us take better care of our patients. Please click on the logout button. 